\title{
Effect of lidocaine on pain caused by nasal pack removal after closed reduction of nasal bone fractures
}

\author{
Ji Yoon Sung ${ }^{1}$, Kyung Dong Kang ${ }^{2}$, Min Wook Kim ${ }^{1}$, Joo Hyoung Kim ${ }^{1}$ \\ ${ }^{1}$ Department of Plastic and Reconstructive Surgery, Pusan National University School of Medicine, Busan; ${ }^{2}$ Gangnam Dr. Woo Plastic Surgery \\ Clinic, Gimhae, Korea
}

Background Pain caused by nasal pack removal after closed reduction of nasal bone fractures is a common problem. This study investigated the effect of infiltrating lidocaine into nasal packs on the pain caused by pack removal after closed reduction of nasal bone fractures. Methods Seventy-five patients who underwent closed reduction of nasal bone fractures between March 2016 and March 2018 were enrolled in this prospective, randomized, singleblind study. Merocel (hydroxylated polyvinyl acetate) packs were applied bilaterally and retained for 5 days. Twenty minutes before removal, both packs were rehydrated with $6 \mathrm{~mL}$ of $2 \%$ lidocaine in 26 patients and with $6 \mathrm{~mL}$ of saline in 24 patients; the packs were not rehydrated in 25 patients. Visual analog scale (VAS) scores for pain on removal were recorded.

Results The mean VAS score was $5.3 \pm 2.0$ in all patients, $3.8 \pm 1.5$ in the lidocaine group, $5.8 \pm 1.4$ in the saline group, and $6.3 \pm 2.1$ in the non-rehydrated group. There was a significant difference in the pain score between the lidocaine and saline groups $(\mathrm{P}<0.001)$ but not between the saline and non-rehydrated groups $(P=0.186)$.

Conclusions Infiltration of lidocaine into Merocel packs reduced the pain caused by pack removal after closed reduction of nasal bone fractures.

Keywords Analgesic / Lidocaine / Nasal surgical procedures / Nasal bone
Correspondence: Joo Hyoung Kim Department of Plastic and Reconstructive Surgery, Pusan National University School of Medicine, 179 Gudeok-ro, Seo-gu, Busan 49241, Korea

Tel: +82-51-240-7269

Fax: +82-51-243-9405

E-mail: medic144@hanmail.net

Received: July 18, $2019 \bullet$ Revised: November 7, $2019 \bullet$ Accepted: November 22, 2019

pISSN: 2234-6163 • elSSN: 2234-6171 • https://doi.org/10.5999/aps.2019.00913• Arch Plast Surg 2020;47:15-19

\section{INTRODUCTION}

Closed reduction of nasal bone fractures is one of the most frequently performed procedures to treat facial bone fractures. After reduction of the nasal bone, packs are inserted into the nasal cavity to support the nasal bone fragments and to prevent postoperative epistaxis. One type of nasal pack is Merocel, which contains hydroxylated polyvinyl acetate, a nonabsorbable material that expands on contact with water after insertion into the nasal cavity [1].

Pain caused by removal of nasal packs after closed reduction of nasal bone fractures is a common problem. There have been reports of reduced pain when these packs are retained for shorter periods, when the sphenopalatine ganglion is blocked, and when preemptive analgesia is used [2-4]. Several studies have suggested that injection of a topical anesthetic agent into nasal packs prior to their removal may reduce pain after septoplasty, although the effects are controversial [5-8]. Moreover, no such 
studies have explored this issue after closed reduction of nasal bone fractures.

The purpose of this study was to investigate the effect of infiltrating lidocaine into nasal packs on the pain caused by pack removal after closed reduction of nasal bone fractures.

\section{METHODS}

\section{Patients and methods}

Seventy-five patients who underwent closed reduction of nasal bone fractures between March 2016 and March 2018 at the plastic and reconstructive surgery department of our institution were included in this prospective, randomized, single-blind study. Patients who had multiple facial bone fractures, those who required a pack on only one side of the nasal cavity, those with impaired clotting, renal disease, or hepatic disease, and those taking medications that could affect the severity of pain were excluded. The study protocol was approved by our institutional ethics committee (IRB No. H-1905-041-079) and performed in accordance with the principles of the Helsinki Declaration of 1975 (revised 2008). All patients provided written informed consent before participating in the trial.

All surgical procedures were performed under general anesthesia by any of four surgeons using the same operative technique and nasal packing method. After reduction of the nasal bone, a 10-cm piece of Merocel was inserted as a pack on each side of the nasal cavity with topical application of gentamicin ointment and inflation with normal saline. The patients remained in the ward for 5 days postoperatively. All nasal packs were removed on day 5 by the same investigator (JYS). Patients who still required analgesics for moderate to severe pain in the 24 hours before removal of the packs were excluded at this point to control for the potentially confounding effects of these agents.

The 75 patients were randomized into three treatment groups using a computer-generated list of random numbers using Microsoft Office Excel software 2007 version (Microsoft Corp., Redmond, WA, USA). In the first group $(\mathrm{n}=26)$, both packs were rehydrated with $6 \mathrm{~mL}$ of $2 \%$ lidocaine 20 minutes before removal; in the second group $(\mathrm{n}=24)$ both packs were rehydrated with $6 \mathrm{~mL}$ of saline; and in the third group $(\mathrm{n}=25)$ the packs were not rehydrated. All patients were blinded to group allocation.

Patients were asked to mark the severity of pain during removal of the nasal packs on a visual analog scale (VAS) with a range of $0-10$ (0, no pain; 10 , the worst pain imaginable) and to complete a questionnaire regarding any nausea, vomiting, dizziness, headache, or other adverse effects that they experienced. All pa- tients were monitored for adverse effects by a physician for 30 minutes after removal of the packs. Patient sex, age, height, and weight data were collected from their medical records. The mean VAS pain scores were compared between the lidocaine and saline groups and between the saline and non-rehydrated groups.

\section{Statistical analysis}

Data for categorical variables are shown as the frequency (number of cases) and those for the quantitative variables as the mean \pm standard deviation, median (interquartile range), and confidence interval as appropriate. The homogeneity of variance was calculated using the Levene test, and it was found not to be equally distributed among the study groups. The data were further found not to be normally distributed using the KolmogorovSmirnov test (age, $\mathrm{P}=0.004$; VAS, $\mathrm{P}<0.001$ ). The distribution of patient demographics was compared using the Kruskal-Wallis $\mathrm{H}$ test (age, $\mathrm{P}=0.283$ ) and the Fisher exact test (sex, $\mathrm{P}=0.251$ ). The Kruskal-Wallis $\mathrm{H}$ test was used to compare continuous variables among the three groups. The Bonferroni correction was used to adjust the significance levels $(P=\alpha / n=0.05 / 3=0.0167)$. A P-value $<0.0167$ was therefore considered to indicate statistical significance. The three median VAS pain scores were not equal according to the robust test $(\mathrm{P}<0.001)$. Statistical analyses were performed using SPSS for Windows software version 25 (IBM Corp., Armonk, NY, USA).

\section{RESULTS}

The patient demographics are shown in Table 1 . The 75 patients (56 male, 19 female) had a mean age of 33 years (range, 7-80 years). The mean VAS pain score was $5.3 \pm 2.0$ in all patients, $3.8 \pm 1.5$ in the lidocaine group, $5.8 \pm 1.4$ in the saline group, and $6.3 \pm 2.1$ in the non-rehydrated group (Table 2, Fig. 1). The difference between the lidocaine and saline groups was statistically significant $(\mathrm{P}<0.001$, Kruskal-Wallis $\mathrm{H}$ test $)$ but the difference between the saline and non-rehydrated groups was not statisti-

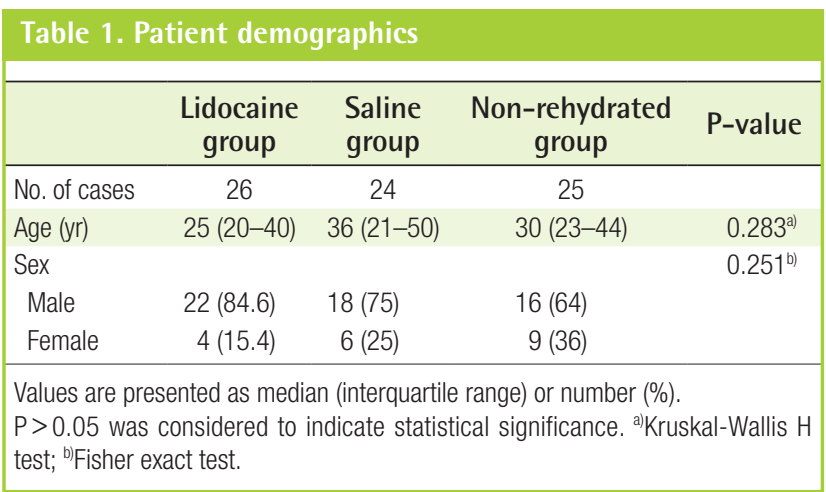


Table 2. Pain scores for the lidocaine and saline groups

\begin{tabular}{|c|c|c|c|}
\hline VAS pain score & $\begin{array}{l}\text { Lidocaine } \\
\text { group }\end{array}$ & $\begin{array}{l}\text { Saline } \\
\text { group }\end{array}$ & P-value ${ }^{a)}$ \\
\hline Score, median (IQR) & $4(3-5)$ & $6(5-7)$ & $<0.001$ \\
\hline \multicolumn{4}{|c|}{$\begin{array}{l}\text { VAS pain score: range } 0-10 \text { ( } 0 \text {, no pain; } 10 \text {, intolerable pain). } \\
\text { VAS, visual analog scale; IQR, interquartile range. } \\
\text { a)Kruskal-Wallis } \mathrm{H} \text { test and the Bonferroni correction ( } P<0.0167 \text { was considered } \\
\text { to indicate statistical significance). }\end{array}$} \\
\hline
\end{tabular}

\section{Fig. 1. VAS pain scores according to treatment group}

The data are shown as the median (interquartile range). VAS, visual analog scale.

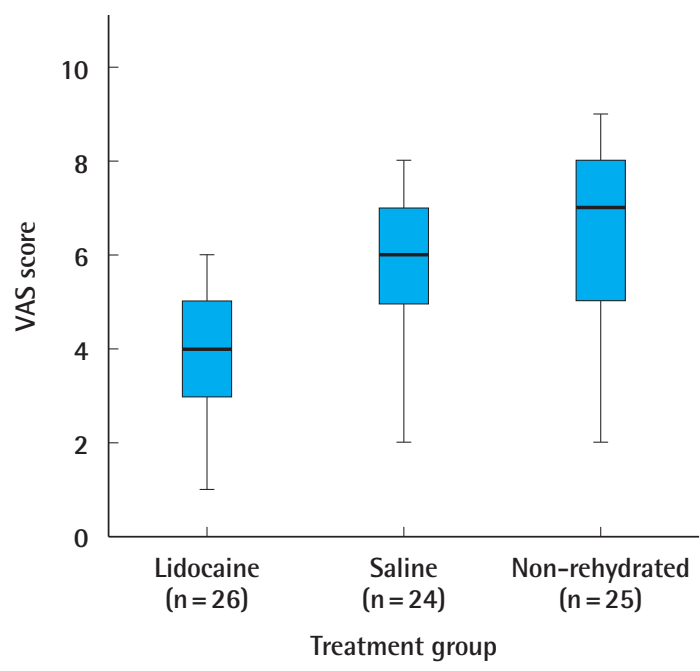

cally significant ( $\mathrm{P}=0.186$, Kruskal-Wallis $\mathrm{H}$ test) (Table 3 ). The difference between the lidocaine and non-rehydrated groups was statistically significant $(\mathrm{P}<0.001$, Kruskal-Wallis $\mathrm{H}$ test) (Table 4). One patient in the lidocaine group developed nausea and two reported dizziness; these symptoms were mild, required no treatment, and resolved within a few minutes. Three patients in the saline group also developed transient nausea that resolved without treatment.

\section{DISCUSSION}

Several reports have investigated the analgesic effect of infiltrating an anesthetic agent into nasal packs before their removal after septoplasty. Lavy et al. [5] rehydrated the nasal pack on one side of the nasal cavity with $5 \mathrm{~mL}$ of $4 \%$ lidocaine $(\mathrm{n}=34)$ and rehydrated the other side with $5 \mathrm{~mL}$ of saline $(\mathrm{n}=34) 10 \mathrm{~min}$ utes before removal of the packs and found no statistically significant difference in pain between the two treatments $(\mathrm{P}=$ 0.0876). Durvasula et al. [6] rehydrated the packs on both sides with lidocaine $(n=29)$ or saline $(n=29) 10$ minutes before re-
Table 3. Pain scores for the saline and non-rehydrated groups

\begin{tabular}{|lccc|}
\hline VAS pain score & $\begin{array}{c}\text { Saline } \\
\text { group }\end{array}$ & $\begin{array}{c}\text { Non-rehydrated } \\
\text { group }\end{array}$ & P-value \\
\hline Score, median (IQR) & $6(5-7)$ & $7(5-8)$ & 0.186 \\
\hline $\begin{array}{l}\text { VAS pain score: range } 0-10 \\
\text { VAS, visual analog scale; IQR, interquartile range. }\end{array}$ \\
$\begin{array}{l}\text { aikruskal-Wallis H test and the Bonferroni correction ( } P<0.0167 \text { was considered } \\
\text { to indicate statistical significance). }\end{array}$ \\
\hline
\end{tabular}

Table 4. Pain scores for the lidocaine and non-rehydrated groups

\begin{tabular}{|lccc|}
\hline VAS pain score & $\begin{array}{c}\text { Lidocaine } \\
\text { group }\end{array}$ & $\begin{array}{c}\text { Non-rehydrated } \\
\text { group }\end{array}$ & P-value \\
\hline Score, median (IQR) & $4(3-5)$ & $7(5-8)$ & $<0.001$ \\
\hline $\begin{array}{l}\text { VAS pain score: range } 0-10 \\
\text { VAS, visual analog scale; IQR, interquartile range. }\end{array}$ \\
$\begin{array}{l}\text { alKruskal-Wallis H test and the Bonferroni correction ( }<<0.0167 \text { was considered } \\
\text { to indicate statistical significance). }\end{array}$ \\
\hline
\end{tabular}

moval and similarly found no statistically significant difference in pain $(\mathrm{P}=0.61)$. In contrast, Lachanas et al. [7] rehydrated one side with $4 \mathrm{~mL}$ of $0.25 \%$ tetracaine $(n=141)$ and the other side with $4 \mathrm{~mL}$ of saline $(\mathrm{n}=141) 10$ minutes before removal and found a significant difference $(\mathrm{P}<0.001)$. Sahin and Aras [8] rehydrated both sides with $10 \mathrm{~mL}$ of $2 \%$ lidocaine $(\mathrm{n}=25)$ or $10 \mathrm{~mL}$ of saline $(\mathrm{n}=25) 10$ minutes before removal and also found a significant difference in pain $(\mathrm{P}<0.001)$. Therefore, the effects of use of topical analgesia during nasal pack removal are controversial. To date, there have been no reports on the effects of topical analgesia before pack removal after closed reduction of nasal bone fractures. In our study, the pain score was significantly lower in the lidocaine group than in the saline group. Topical anesthetic agents can block the neural transmission of electrical impulses when applied to the nasal mucosa [9].

The ideal anesthetic agent should be safe, short-acting, and inexpensive. We selected $2 \%$ lidocaine as the topical analgesic to be used in this study. Lidocaine (N-diethylaminoacetyl-2,6-xylidide) is a local anesthetic of the amide type and has a short time to onset of effect and an intermediate duration of action. Lidocaine is known to be a safe topical analgesic agent and is commonly used on the nasal mucosa [10]. Lidocaine is systemically absorbed into the airway after topical application, and then the liver metabolizes it into monoethylglycinexylidide and glycinexylidide, its active metabolites. It shows varying patterns of toxicity according to its plasma concentration; the accepted therapeutic range for controlling arrhythmias and avoiding toxicity in adults is $1.5-5 \mu \mathrm{g} / \mathrm{L}[11]$. In healthy adults, the mean plasma half-life of lidocaine is 70-200 minutes. Three patients in our study developed mild complications (nausea and dizziness) af- 
ter infiltration of lidocaine; all recovered within a few minutes with no specific treatment.

We attribute the conflicting data on analgesic effects in previous studies to variation in the time to onset of action of the various topical anesthetic agents used. The peak concentration of lidocaine when applied to the nasal mucosa is 20 minutes [12,13]; however, there is limited information available on the pharmacological effects of lidocaine administered topically via the intranasal route. Before designing this study, we performed a pilot trial in which we assumed that 10 minutes would not be long enough for the infiltration of lidocaine to have an analgesic effect, and that at least 20 minutes would be needed. In our pilot study, $6 \mathrm{~mL}$ of lidocaine on each side was sufficient to soak the Merocel adequately without drops of lidocaine solution reaching behind the nasal cavity.

This study has several limitations. First, the closed reductions of nasal bone fractures were performed by four different surgeons. Although all four surgeons were instructed to use the same Merocel packing method to reduce bias, we cannot exclude the possibility of slight differences in the packing method used. Second, there might have been variations in the degree of injury of nasal mucosa according to the severity of the nasal bone fracture and the different operating styles of the four surgeons. Third, the study had a single-blind design (i.e., the clinician who removed the nasal packs was aware of the group allocation), which could have introduced a degree of observer bias. Fourth, the sample size was small. Therefore, a larger double-blind casecontrol study in which the same surgeon performs all operations is needed in the future.

In conclusion, infiltration of lidocaine into Merocel packs reduced the pain caused by nasal pack removal after closed reduction of nasal bone fractures.

\section{NOTES}

\section{Conflict of interest}

No potential conflict of interest relevant to this article was reported.

\section{Ethical approval}

The study was approved by the Institutional Review Board of Pusan National University Hospital (IRB No. H-1905-041-079) and performed in accordance with the principles of the Declaration of Helsinki. Written informed consents were obtained.

\section{Author contribution}

Conceptualization: Sung JY, Kang KD. Data curation: Sung JY. Formal analysis: Kim JH, Kim MW. Methodology: Kang KD.
Project administration: Kim JH. Writing original draft: Sung JY. Writing - review \& editing: Kim JH, Sung JY. Approval of final manuscript: all authors.

\section{ORCID}

Ji Yoon Sung https://orcid.org/0000-0001-6925-8120 Kyung Dong Kang https://orcid.org/0000-0002-5251-6565

Min Wook Kim https://orcid.org/0000-0001-8024-3608

Joo Hyoung Kim https://orcid.org/0000-0002-4893-3761

\section{REFERENCES}

1. Ruddy J, Brain D, Sudesh RR, et al. A prospective trial of Merocel packs. Rhinology 1991;29:281-5.

2. Hwang JH, Liu CM, Liu TC, et al. Sphenopalatine ganglion block before removal of nasal packing. Laryngoscope 2003; 113:1423-4.

3. Choi DS, Lee JW, Yang JD, et al. Minimal packing duration in close reduction for nasal bone frcture treatment. J Plast Surg Hand Surg 2015;49:275-9.

4. Yilmazer C, Sener M, Yilmaz I, et al. Pre-emptive analgesia for removal of nasal packing: a double-blind placebo controlled study. Auris Nasus Larynx 2007;34:471-5.

5. Lavy JA, Small GV, Jay N, et al. A prospective randomized controlled study of $4 \%$ lignocaine solution in Merocel nasal pack removal. Rhinology 1996;34:219-21.

6. Durvasula VS, Brewis C, Syeda F, et al. Lignocaine as a topical analgesia for post-operative nasal pack removal: a prospective, randomized, double-blind, controlled trial. J Laryngol Otol 2005;119:348-51.

7. Lachanas VA, Karatzias GT, Pinakas VG, et al. The use of tetracaine $0.25 \%$ solution in nasal packing removal. Am J Rhinol 2006;20:483-4.

8. Sahin C, Aras HI. Effect on patient anxiety of lidocaine infiltration into nasal packing after septoplasty: prospective, controlled study. J Laryngol Otol 2015;129:784-7.

9. Ozkiris M, Kapusuz Z, Saydam L. Comparison of ropivacaine, bupivacaine and lidocaine in the management of posttonsillectomy pain. Int J Pediatr Otorhinolaryngol 2012;76: 1831-4.

10. Ozkiris M, Aydin R, Gencer ZK, et al. Comparison of topical anesthetic effects of lidocaine, prilocaine, ropivacaine, and bupivacaine in transnasal fiberoptic nasopharyngolaryngoscopy. Am J Rhinol Allergy 2014;28:e141-3.

11. Melby MJ, Raehl CL, Kreul JF. Pharmacokinetics of endotracheally administered lidocaine. Clin Pharm 1986;5:22831.

12. Loukides S, Katsoulis K, Tsarpalis K, et al. Serum concen- 
trations of lignocaine before, during and after fiberoptic bronchoscopy. Respiration 2000;67:13-7.

13. List T, Mojir K, Svensson P, et al. A new protocol to evaluate the effect of topical anesthesia. Anesth Prog 2014;61:13544. 